\title{
Discoloration and Dissolution of Titanium and Titanium Alloys with Immersion in Peroxide- or Fluoride-containing Solutions
}

\author{
Tatsumi NOGUCHI, Shinji TAKEMOTO, Masayuki HATTORI, Masao YOSHINARI, Eiji KAWADA and \\ Yutaka ODA \\ Department of Dental Materials Science, Tokyo Dental College, 1-2-2 Masago, Mihama-ku, Chiba 261-8502, Japan \\ Corresponding author, Yutaka Oda; E-mail: yoda@tdc.ac.jp
}

Received July 18, 2007/Accepted August 30, 2007

\begin{abstract}
This study compared differences in discoloration and dissolution in several titanium alloys with immersion in peroxide- or fluoride-containing solution. Commercially pure titanium (CP-Ti) and six titanium-based alloys were used: Ti-0.15Pd, Ti$6 \mathrm{Al}-4 \mathrm{~V}$, Ti-7Nb-6Al, Ti-55Ni, Ti-10Cu, and Ti-20Cr. Two test solutions were prepared for immersion of polished titanium and titanium alloys: one consisting of $0.2 \% \mathrm{NaF}+0.9 \% \mathrm{NaCl}\left(\mathrm{pH} 3.8\right.$ with lactic acid) and the other of $0.1 \mathrm{~mol} / \mathrm{l} \mathrm{H}_{2} \mathrm{O}_{2}+$ $0.9 \% \mathrm{NaCl}$ ( $\mathrm{pH} 5.5$ ). Following immersion, color changes were determined with a color meter and released elements were measured using ICP-OES. Discoloration and dissolution rates differed between the two solutions. In the hydrogen peroxide-containing solution, color difference was higher in Ti-55Ni and Ti-6Al-4V than in any of the other alloys, and that Ti$55 \mathrm{Ni}$ showed the highest degree of dissolution. In the acidulated fluoride-containing solution, CP-Ti, Ti-0.15Pd, Ti-6Al-4V, Ti-7 Nb-6Al, and Ti-10Cu alloys showed remarkable discoloration and dissolution with immersion. On the contrary, Ti-20Cr alloy showed very little discoloration and dissolution in either solution.
\end{abstract}

Keywords: Corrosion, Discoloration, Titanium alloys

\section{INTRODUCTION}

In recent years, titanium implants and prostheses have come into wide use in clinical dentistry. However, there have been reports of pigmentation and discoloration occurring with the practical application of titanium implants and denture bases ${ }^{1-3)}$.

Although titanium is well known for its superior corrosion resistance, it is not strongly resistant to corrosion caused by fluoride. Probster et al. noted that prophylactic agents containing fluoride must be used with great care on implant materials and crown restorations made of titanium ${ }^{4}$. Ozeki et al. reported that titanium and titanium alloys were resistant to dentifrices containing fluoride up to a concentration of $1,000 \mathrm{ppm}$, but were severely corroded by acidic topical agents containing approximately 9,000 ppm of fluoride ${ }^{5}$. Oda et al. also reported that the corrosion resistance of titanium was insufficient in the presence of $0.5 \%$ or higher concentrations of sodium fluoride ${ }^{6}$. Moreover, Nakagawa et al. reported that the passive film on titanium surface was destroyed under conditions where $30 \mathrm{ppm}$ or more hydrofluoric acid was generated by dissociation of sodium fluoride ${ }^{7}$. In summary, these reports indicated fluoride as a possible cause of discoloration in titanium prostheses.

Separately, Pan et al. reported that peroxide was produced by bacteria and leukocytes during inflammatory reactions, and that it attacked titanium surfaces $^{8,9)}$. In the same vein, in vitro studies have reported on decrease in resistance to corrosion and signs of pitting corrosion in titanium in the presence of hydrogen peroxide ${ }^{10,11}$. Furthermore, Abe et $a l$. noted severe discoloration with highly alkaline, peroxide-containing denture cleaners ${ }^{12)}$.

Taken together, these reports ${ }^{4-12)}$ suggested that peroxide produced by inflammatory cells and fluoride-containing prophylactic agents caused discoloration in titanium and titanium alloys. Therefore, although the mechanical properties and biocompatibility of titanium and titanium alloys are excellent, discoloration resistance in an oral environment remains a major challenge.

In view of the discoloration problem plaguing titanium alloys in practical application, this study was undertaken with two-fold aims: (1) to compare metal release and discoloration in several titanium alloys with exposure to peroxide- and acidulated fluoride-containing solutions; and (2) to determine whether there was any association between discoloration and oxide film formation or dissolution.

\section{MATERIALS AND METHODS}

\section{Alloy specimens}

Commercially available pure titanium (KS50, JIS type 2, Kobe Steel Industry; TI) and four titaniumbased alloys were used, together with two experimental alloys (Table. 1). Pd-containing titanium alloy (TPD) is a corrosion-resistant titanium used in industry. Ti-6Al-4V (TAV) and Ti-7Nb-6Al (TNB) alloys are widely used for denture bases. Ti$\mathrm{Ni}$ (TNI) alloy is used for orthodontic appliances. Copper- or chromium-containing alloys (TCU, TCR) were experimental alloys used in the development of dental casting alloys. These experimental copper- and chromium-containing alloys were made by 
Table 1 Titanium and titanium alloys used

\begin{tabular}{llll}
\hline Metal & Composition (mass \%) & Manufacturer & Code \\
\hline Grade2-Ti & Ti>99.5 & Kobe steel & TI \\
Ti-Pd & Ti-0.15Pd & Kobe steel & TPD \\
Ti-Al-V & Ti-6Al-4V & Kobe steel & TAV \\
Ti-Nb-Al & 86.5Ti-7.0Nb-6.0Al-0.5Bal & GC & TNB \\
Ti-Ni & Ti-55Ni & Daido & TNI \\
Ti-Cu & Ti-10Cu & Experimental & TCU \\
Ti-Cr & Ti-20Cr & Experimental & TCR \\
\hline
\end{tabular}

melting titanium sponge $(99.8 \%$ or above, Sumitomo Titanium, Amagasaki, Japan), copper (99.99\% minimum purity, Research Institute for Electric and Magnetic Materials, Sendai, Japan) and chromium (99.99\%, JMC New Materials Inc., Tokyo, Japan) into 20 -g buttons in an argon-arc melting furnace (ACM-01, Diavac, Chiba, Japan). Obtained alloy buttons were arc-melted and cast in an aluminamagnesia mold (Titavest CB, J. Morita, Kyoto, Japan) using an argon-arc melting/pressure casting machine (Cyclarc II, J. Morita, Kyoto, Japan).

Specimens of $14 \times 14 \times 1 \mathrm{~mm}$ or $\phi 20 \times 1 \mathrm{~mm}$ size were cut from a sheet or rod of commercially available titanium or titanium alloy, while experimental titanium alloy specimens were cast using a wax pattern of the same size. Each specimen was embedded in epoxy resin (1-inch EX-ring, Refine Tech Co., Yokohama, Japan), and the alloy surface was polished with abrasive paper according to the standard metallurgical procedure. Polishing was completed with $0.02-\mu \mathrm{m}$ colloidal silica particles and ultrasonic washing in distilled water for 10 minutes.

\section{Test solutions}

Two solutions were prepared for the discoloration and dissolution tests. An acidulated fluoride solution containing $0.2 \% \mathrm{NaF}$ with $0.9 \% \mathrm{NaCl}(\mathrm{pH} 3.8$ with lactic acid; NF), whereby its concentration was similar to that of fluoride in dental prophylactic agents used for mouth rinses. The low $\mathrm{pH}$ was intended to accelerate the effect on titanium. The other test solution consisted of $0.1 \mathrm{~mol} / \mathrm{l} \mathrm{H}_{2} \mathrm{O}_{2}$ with $0.9 \% \mathrm{NaCl}$ ( $\mathrm{pH} 5.5 ; \mathrm{HO}$ ), whereby its concentration was similar to that of peroxide in body fluids with inflammatory response ${ }^{8)}$. Analytical grade reagents (Wako Chem., Osaka, Japan) were used for the preparation of these two test solutions.

\section{Discoloration measurement}

Polished titanium and titanium alloy specimens were mounted on an immersion device and dipped in the test solution for 15 seconds per one-minute block, with the temperature controlled at $23 \pm 1^{\circ} \mathrm{C}$ according to ISO $10271^{13)}$. With the NF solution, the immersion period was one hour. With the HO solution, specimens were immersed for periods of 24,72 , and 168 hours in consideration of the slowness of color change. Following immersion, color changes were determined with a color meter (MCR-A, Minolta, Japan). Color values and amounts of color change were determined according to the CIE L*a* $b^{*}$ color coordinator system. Color difference was calculated using the following equation:

$$
\Delta \mathrm{Eab}^{*}=\left[\left(\mathrm{L}^{*}-\mathrm{L}_{0} *\right)^{2}+\left(\mathrm{a}^{*}-\mathrm{a}_{0} *\right)^{2}+\left(\mathrm{b}^{*}-\mathrm{b}_{0}\right)^{2}\right]^{1 / 2}
$$

where $\mathrm{L}_{0}{ }^{*}, \mathrm{a}_{0}{ }^{*}, \mathrm{~b}_{0}{ }^{*}$ were values before immersion, while $L^{*}, a^{*}, b^{*}$ were values after immersion.

\section{Dissolution measurement}

Polished titanium and titanium alloy specimens were immersed in $20 \mathrm{ml}$ of each test solution in a glass vial. The polished surface was exposed to NF solution for one hour and HO solution for 168 hours. Following immersion, the released elements were measured using ICP-OES (Vista-MPX, SII, Japan). Detection limit was below $0.01 \mathrm{ppm}$.

\section{SEM observation}

Following immersion, the surface of each sample was observed using a field emission scanning electron microscope (JSM-6340F, JEOL, Japan).

\section{Statistical analysis}

Color difference in, and the quantity of each metal released from, each alloy were statistically analyzed with two-way analysis of variance (ANOVA, $p<0.05$ ) to determine the effects of alloy type and solution type. One-way ANOVA and Scheffé's test ( $\alpha=$ 0.05) were used to compare the specimen groups for significant differences in the color difference and total amount of released elements.

\section{RESULTS}

\section{Discoloration}

Change in color with time of immersion in the HO solution is shown in Fig. 1. TNI and TAV alloys showed a distinct increase in color difference with time. The other alloys showed a color change of less than 5 units, indicating that visual detection of discoloration would be difficult.

Figure 2 shows the color difference in the titanium alloys in both solutions. The given values represented changes in color after 168 hours in HO solution and one hour in NF solution. TAV and TNI alloys showed a remarkable change in color in the HO solution. TI, TPD, TAV, TNB, and TCU alloys showed similar degrees of color change in the $\mathrm{NF}$ solution, with color difference values ranging around 20. On the contrary, TCR alloy showed the least 
Table 2 Amounts of detected elements in hydrogen peroxide- and fluoride-containing solutions after immersion of titanium and titanium alloys

\begin{tabular}{|c|c|c|c|c|}
\hline Alloy & & HO $168 \mathrm{~h}$ & & NF $1 \mathrm{~h}$ \\
\hline TI & $\mathrm{Ti}: 0.34$ & & $\mathrm{Ti}: 8.89$ & \\
\hline TPD & $\mathrm{Ti}: 0.34$ & & $\mathrm{Ti}: 7.42$ & \\
\hline TAV & $\mathrm{Ti}: 0.72$ & $\mathrm{Al}: 0.01 \quad \mathrm{~V} \quad: 0.04$ & $\mathrm{Ti}: 5.51$ & $\mathrm{Al}: 0.03 \mathrm{~V} \quad: 0.19$ \\
\hline TNB & $\mathrm{Ti}: 0.75$ & $\mathrm{Al}: 0.02 \quad \mathrm{Nb}: 0.15$ & $\mathrm{Ti}: 8.17$ & $\mathrm{Al}: 0.07 \mathrm{Nb}: 0.57$ \\
\hline TNI & $\mathrm{Ti}: 2.63$ & $\mathrm{Ni}: 3.45$ & $\mathrm{Ti}: 1.51$ & $\mathrm{Ni}: 1.78$ \\
\hline TCU & $\mathrm{Ti}: 0.10$ & $\mathrm{Cu}: 0.06$ & $\mathrm{Ti}: 6.54$ & \\
\hline TCR & $\mathrm{Ti}: 0.35$ & $\mathrm{Cr}: 0.09$ & $\mathrm{Ti}: 0.07$ & \\
\hline
\end{tabular}

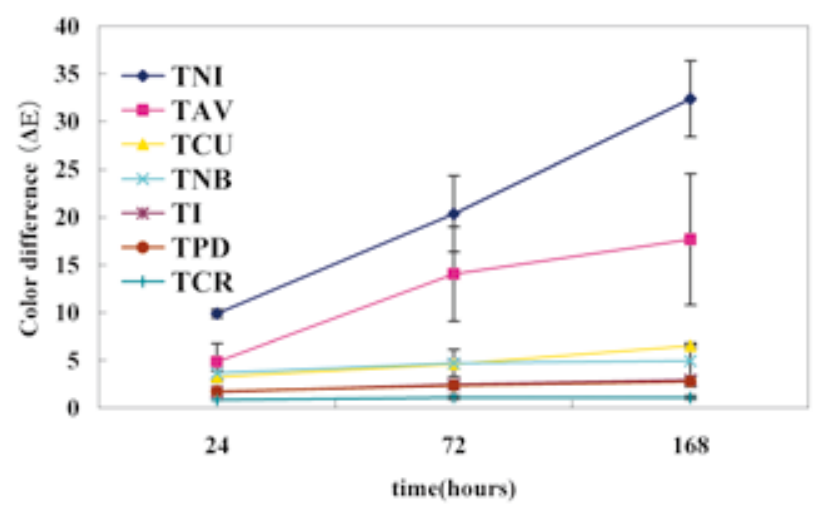

Fig. 1 Change in color in titanium alloys in HO solution.

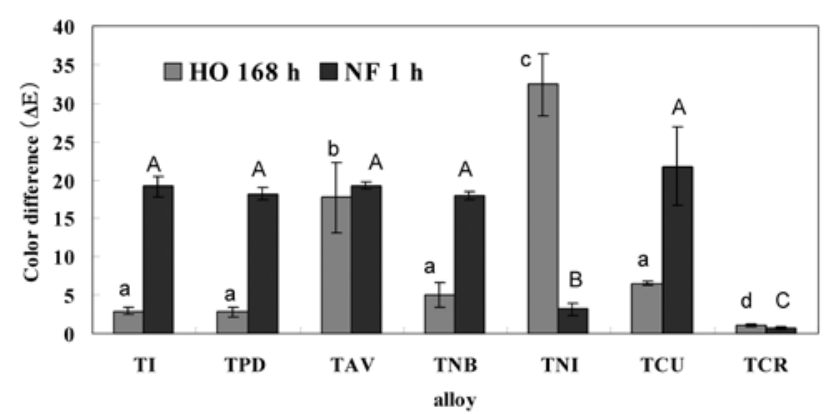

Fig. 2 Color difference in titanium alloys in both solutions. Means with the same superscript letter are not significantly different at $\mathrm{p}<0.05$.

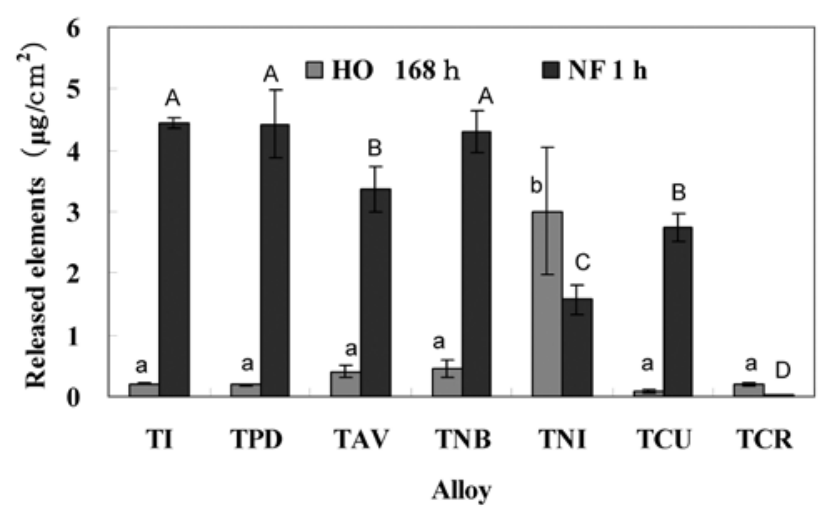

Fig. 3 Total amount of released elements in each solution. Means with the same superscript letter are not significantly different at $\mathrm{p}<0.05$.

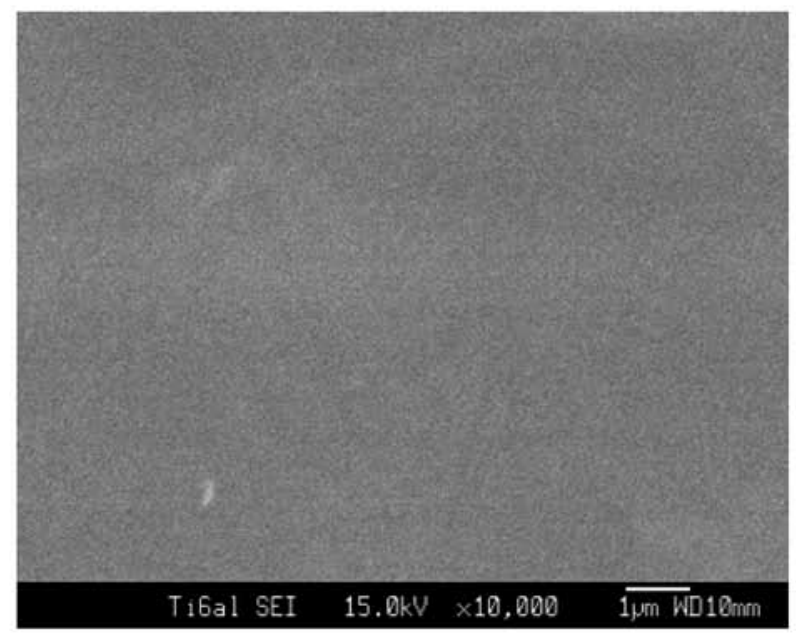

\section{TAV}

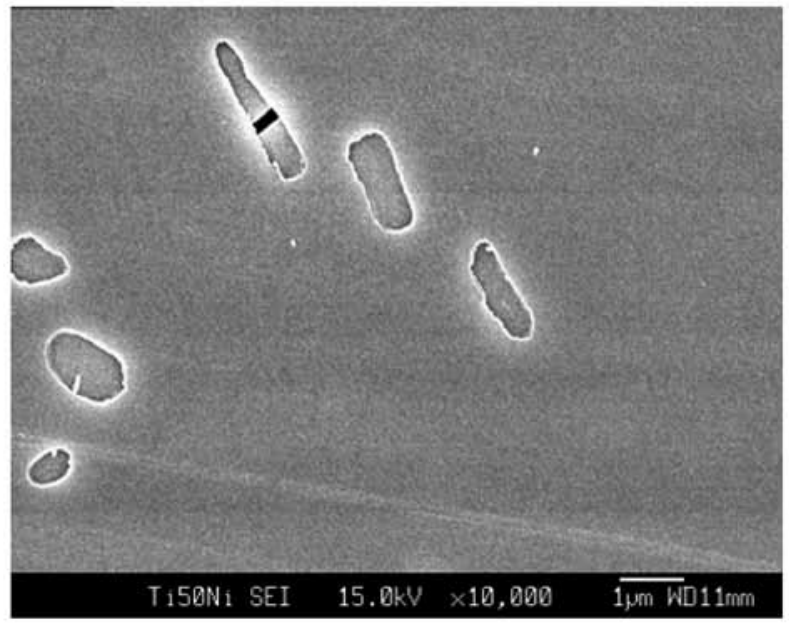

\section{TNI}

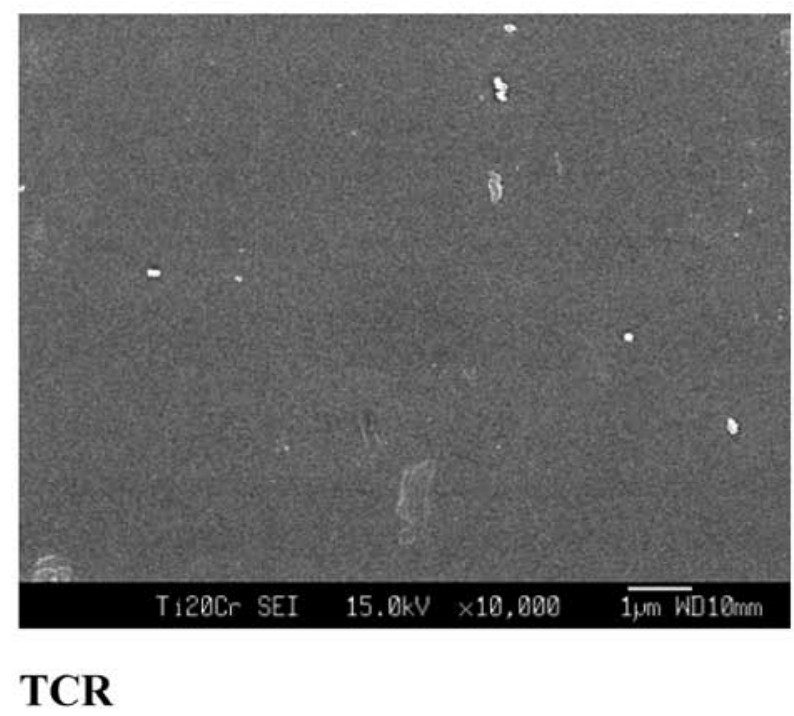

Fig. 4 SEM images of alloy surface after immersion in HO solution. 


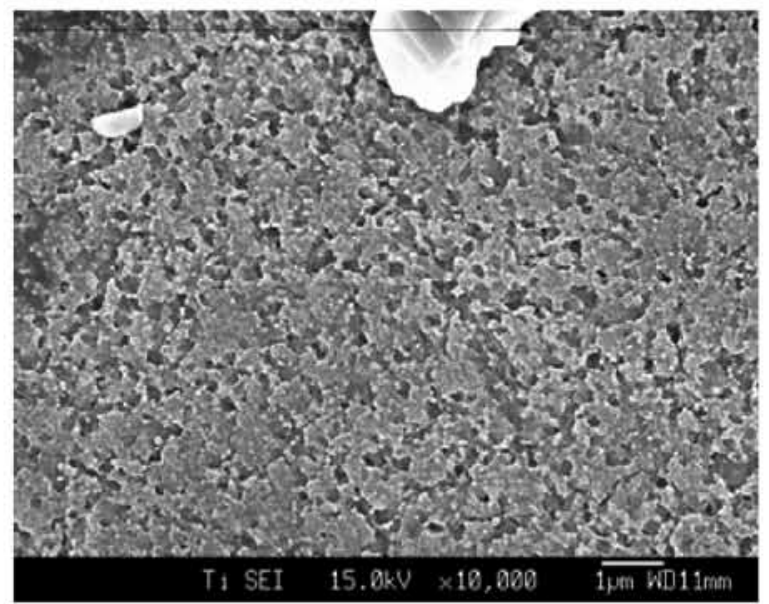

TI

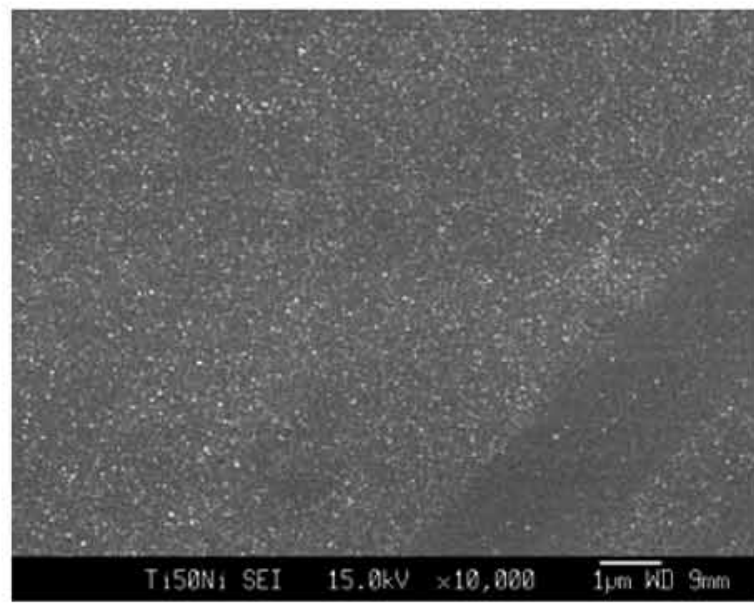

TNI

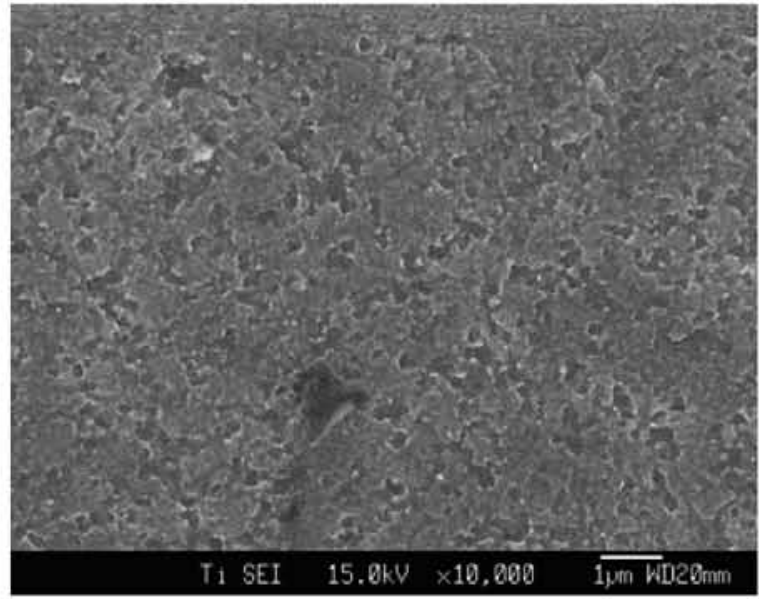

\section{TCU}

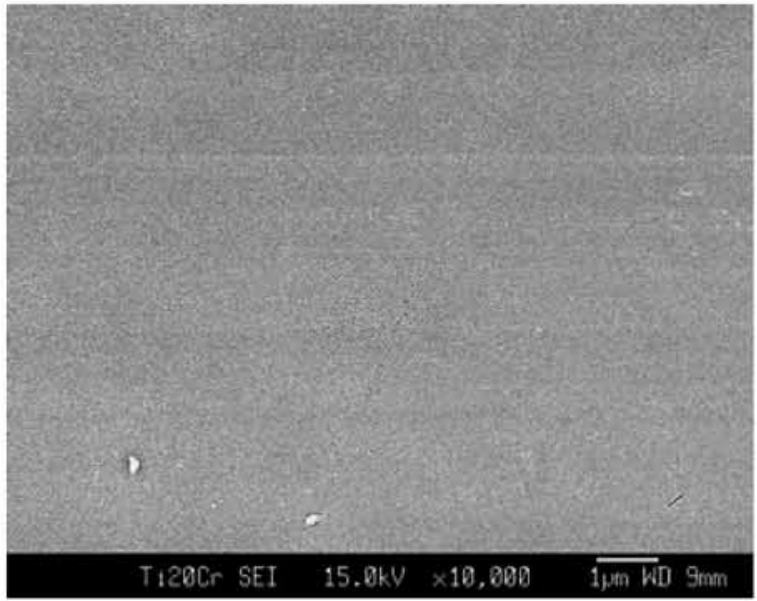

\section{TCR}

Fig. 5 SEM images of alloy surface after immersion in NF solution.

color difference in both solutions.

\section{Dissolution}

Table 2 shows the detected elements in $\mathrm{HO}$ and $\mathrm{NF}$ solutions after immersion of titanium and titanium alloy specimens. Titanium was detected in both $\mathrm{HO}$ and $\mathrm{NF}$ solutions for every alloy. In the $\mathrm{HO}$ solution, release of almost all the constituent elements of each alloy was detected, while $\mathrm{Cu}$ and $\mathrm{Cr}$ were under the detection limit in the NF solution.

Figure 3 shows the total amounts of released elements in both solutions. TNI alloy showed remarkable dissolution in the HO solution, whereas TCU alloy showed the least dissolution in HO solution. TI, TPD, and TNB alloys showed higher dissolution than the other alloys in the NF solution. On the contrary, TCR alloy showed the least dissolution in $\mathrm{NF}$ solution.

\section{SEM observation}

Figure 4 shows the typical surface morphologies of the samples following immersion in $\mathrm{HO}$ solution. TNI alloy showed some pitting and holes on the surface. As for the other alloys in $\mathrm{HO}$ solution (such as TAV and TCR in Fig. 4), no remarkable changes in their surface morphology were observed.

In terms of surface morphology after immersion in NF solution, Fig. 5 shows that those of TI, TNI, TCU, and TCR differed from each other. TI showed a rough and porous profile, whereas TNI showed a minute granular profile. TCU showed a moderately rough and porous profile, whereas TCR showed a smooth surface. As for TPD, TAV, and TNB alloys, they showed a surface morphology similar to that of TI samples. 


\section{DISCUSSION}

Over the last few decades, the increasing use of titanium and titanium alloy dental implants has raised hopes for the treatment of partially or completely edentulous patients. Studies on the corrosion resistance of titanium are generally performed by incubating $\mathrm{Ti}$ in saline or artificial saliva. In such solutions, titanium exhibits a superior corrosion resistance due to the presence of a stable and dense titanium oxide film that spontaneously covers the metal surface. However, despite its excellent corrosion resistance when tested in vitro, titanium has been reported to be sensitive to sodium fluoride $^{1,3-6)}$ and hydrogen peroxide ${ }^{7-11)}$. Against this background, this study sought to investigate the effects of peroxide- and fluoride-containing solutions on discoloration and metal release in several titanium alloys. Generally, the corrosion resistance behaviors of titanium-based alloys do not differ much in artificial saliva ${ }^{14)}$. In this connection, the null hypotheses in this study were that the amount of metal elements released does not differ among titanium-based alloys, and that discoloration correlates with dissolution.

The sodium fluoride content of commercially fluoridated mouth rinses and topical application gels is between $0.1 \%$ and $2 \%$. The standard prescription for fluoride mouth-rinsing agents is $0.2 \% \mathrm{NaF}$ $\left(\mathrm{F}^{-}: 905 \mathrm{ppm}\right)$ for weekly rinsing. In vitro studies have reported that corrosion of CP-Ti can occur at a concentration of $0.2 \% \mathrm{NaF}$, and that an acid medium can enhance fluoride activity and accelerate corrosion rate $^{4-6)}$. In the present study, we selected acidulated sodium fluoride solution at a concentration of $0.2 \%$ $\mathrm{NaF}$ to induce corrosion. Apart from fluoride, hydrogen peroxide - produced by bacteria and leukocytes during inflammatory reactions - has been shown to attack titanium surfaces. Several authors have investigated the effects of hydrogen peroxide on titanium corrosion at a concentration range of $0.05-0.15$ $\mathrm{mol} / \mathrm{l}^{7,9)}$. In the present study, a solution with a concentration of $0.1 \mathrm{~mol} / 1 \mathrm{H}_{2} \mathrm{O}_{2}$ with $0.9 \% \mathrm{NaCl}(\mathrm{pH} 5.5$ ) was selected to induce corrosion.

Color differences were classified into six ranks: $\Delta \mathrm{Eab}^{*}=0.5-1.5$, slight; $\Delta \mathrm{Eab}^{*}=1.5-3.0$, noticeable; $\Delta \mathrm{Eab}^{*}=3.0-6.0$, appreciable; $\Delta \mathrm{Eab}^{*}=6.0-$ 12.0 , much; $\Delta \mathrm{Eab}^{*}=12.0-$, very much ${ }^{15}$. TNI and TAV alloys showed a remarkable color difference of more than 12.0 in HO solution. TI, TPD, TAV, TNB, and TCU alloys also showed remarkable color difference of more than 12.0 in NF solution. A plausible explanation for the remarkable color difference observed in this experiment pointed to the formation of a thick oxide film or increased surface roughness due to corrosion. Color difference was calculated from differences in $L^{*}, a^{*}$, and $b^{*}$ values.
The formation of an oxide film would contribute substantially to differences in $a^{*}$ and $b^{*}$ values, while surface roughness would contribute substantially to differences in $\mathrm{L}^{*}$ value. In the case of TAV that showed much color difference in HO solution, it was the difference in $b^{*}$ value that accounted for much of the color difference. On the contrary, when TNI showed much color difference in $\mathrm{HO}$ solution, it was the difference in $\mathrm{L}^{*}$ value that accounted for much of the color difference.

The surfaces of titanium and titanium alloys consist of a thin oxide layer $(2-6 \mathrm{~nm})$. This oxide layer is amorphous or poorly crystalline, and is composed of a slightly oxygen-deficient titanium oxide $^{16,17)}$. When titanium is brought into contact with hydrogen peroxide, a phenomenon will take place at the metal interface. Titanium decomposes the hydrogen peroxide, and oxide film is formed by oxidation reaction. In other words, the hydrogen peroxide behaves as an oxidizing agent and catalyzes the formation of a titanium oxide film ${ }^{18,19)}$. This oxide film is far thicker than the one obtained by simple immersion of the metal in saline solutions for similar periods ${ }^{13)}$. When the oxide layer develops to a thickness in the order of $40 \mathrm{~nm}$, interference with color occurs $^{7}$.

Conversion of fluoride ions into hydrofluoric acid partially depends on the $\mathrm{pH}$ of the solution. Hydrofluoric acid attacks passive films on the titanium surface ${ }^{6,20)}$. This attack is preferentially targeted toward loosely packed atoms, thus revealing grain boundaries and increasing surface roughness. Consequently, a high degree of color difference occurs.

Dissolution is the most obvious indicator of corrosion. The correlation between color difference and the total amount of released elements in the hydrogen peroxide-containing solution is shown in Fig. 6. TNI alloy showed a high degree of dissolution and color difference. SEM observation of the same disks also recognized signs of roughness. This implied that the main reason for this discoloration was corrosion. As for the TAV alloy, a high degree of color difference was observed despite its lower dissolution. This implied that the main reason for this discoloration was the formation of a thick oxide film. Titanium-nickel alloy is potentially susceptible to release of $\mathrm{Ni}$ ions in $\mathrm{NaCl}$ solution ${ }^{21-23}$. Although the mechanism of titanium-nickel alloy corrosion in hydrogen peroxide-containing solution remained to be fully clarified, its dissolution rate seemed to be accelerated by the presence of hydrogen peroxide.

The correlation between color difference and the total amount of released elements in the fluoridecontaining solution is shown in Fig. 7. Evidently, almost all of the discoloration was caused by dissolution, especially in TI, TPD, TAV, TNB, and 


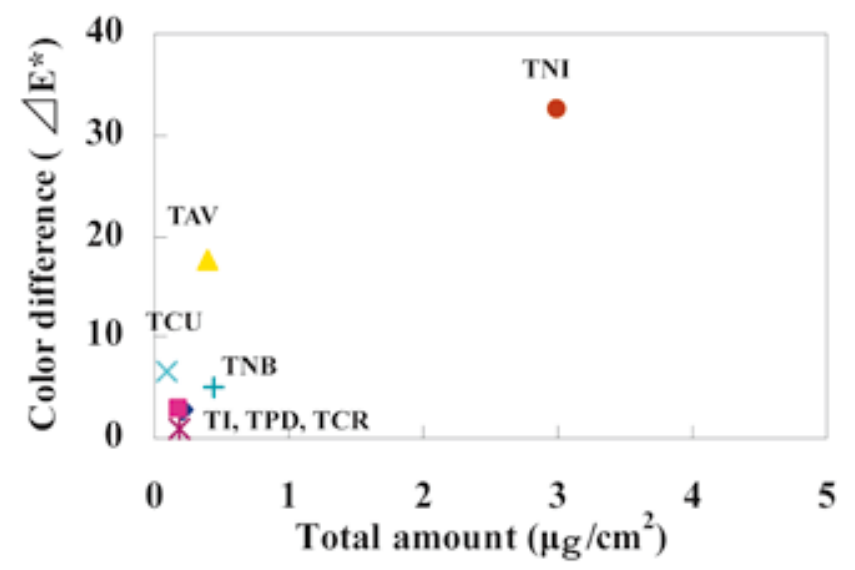

Fig. 6 Total amount of released elements us color difference in HO solution.

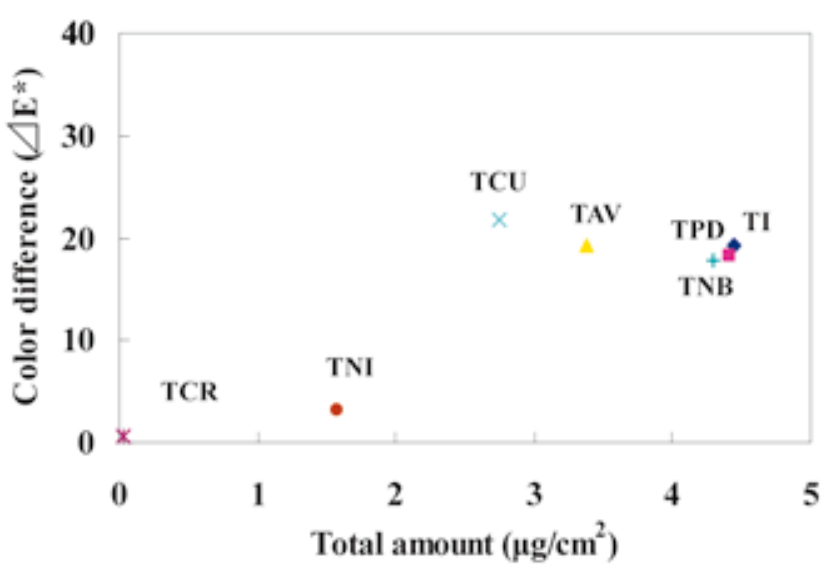

Fig. 7 Total amount of released elements us color difference in NF solution.

TCU alloys. However, TCR alloy showed no distinct changes. It appeared that the titanium alloys were chemically attacked in the presence of sodium fluoride, releasing $\mathrm{Ti}$ ions into the solution, except for titanium alloy containing chromium.

The corrosion resistance of a titanium alloy is related to its composition. For example, the greatest increase in corrosion resistance is obtained when titanium is alloyed with cathodic additions capable of shifting the corrosion potential of the alloy in the noble direction (for instance, by palladium) and also by metals which increase the tendency of titanium to passivate ${ }^{24}$. It was also noted that, when the aluminum content increased in titanium alloy, the passive potential region extended with a concomitant decrease in titanium corrosion rate ${ }^{25)}$. Conversely, the addition of copper and nickel decreased the breakdown potential of titanium alloy with a subsequent decrease in corrosion resistance $^{21,26)}$. From these viewpoints, it would seem that palladium- or aluminum-containing alloys would show excellent corrosion resistance in fluoridecontaining solution. However, in this study, TPD alloy showed no remarkable difference from pure titanium. It should be noted that all the abovementioned observations were based on exposure to nearneutral chloride solutions. Brossia and Cragnolino ${ }^{27)}$ reported that although palladium addition significantly affected the localized corrosion resistance of titanium, palladium did not appear to influence the passive corrosion rate nor mitigate the deleterious effects of fluoride. Our results in the present study were generally in line with those of Brossia and Cragnolino ${ }^{27)}$.

On the other hand, TCR alloy exhibited superior corrosion resistance in both solutions. It was presumed that chromium oxide on the TCR alloy played a significant role in the latter's high corrosion resistance to fluoride. Titanium oxides on the TCR alloy dissolved in the fluoride-containing solution, whereas chromium oxide barely dissolved. Consequently, a chromium-rich oxide film formed on the TCR alloy, suppressing dissolution of titanium and preventing fluoride attack ${ }^{28)}$. It is noteworthy that in this study, ion leakage from the titanium alloys was higher in acidic sodium fluoride solution - except with TCR alloy. This exception thus highlighted the role of additive chromium in corrosion resistance in titanium alloys.

One of our null hypotheses was that the amount of metal elements released does not differ among the titanium-based alloys. However, the total amount of released elements differed not only with difference in solution type, but also with difference in the constituent elements of the alloys. Consequently, this null hypothesis was rejected. Indeed, it was clearly shown that additive elements of titanium alloys played an important role in corrosion resistance.

The other null hypothesis was that discoloration correlates with dissolution. Although the TAV alloy showed a remarkable color difference in the hydrogen peroxide-containing solution, it hardly showed any dissolution. In other words, the discoloration of titanium alloys stemmed from a variety of causes, with the most likely candidates being oxide film formation and dissolution.

\section{CONCLUSIONS}

We investigated the discoloration and dissolution of several titanium alloys with exposure to hydrogen peroxide- or acidulated sodium fluoride-containing solution.

The degrees of discoloration and dissolution differed between the two solutions. In the hydrogen peroxide-containing solution, the degree of discoloration was higher in $\mathrm{Ti}-\mathrm{Ni}$ and $\mathrm{Ti}-\mathrm{Al}-\mathrm{V}$ alloys than 
in any of the other alloys. In the acidulated sodium fluoride-containing solution, Ti, Ti-Pd, Ti-Al-V, Ti$\mathrm{Nb}-\mathrm{Al}$, and Ti-Cu alloys showed remarkable discoloration and dissolution. As for Ti-Cr alloy, it showed very little discoloration and dissolution in either solution.

Taken together, these results implied that the mechanism of discoloration in titanium alloys differed according to solution type - whether it contained peroxide or fluoride.

\section{ACKNOWLEDGEMENTS}

This study was supported in part by a Grant-inaid for Developmental Scientific Research from the Ministry of Education, Science, Culture and Sports, Japan. We would also like to thank Associate Professor Jeremy Williams, Tokyo Dental College, for his assistance with the English proofreading of this manuscript.

\section{REFERENCES}

1) Lausmaa J, Kasemo B, Hansson S. Accelerated oxide growth on titanium implants during autoclaving caused by fluoride contamination. Biomaterials 1985; 6: 23-27.

2) Soma H, Imamura $Y$. The circumstances of cast titanium prosthesis. Quintessence of Dent Tech 2001; 26: 462-473.

3) Sutton AJ, Rogers PM. Discoloration of a titanium alloy removable partial denture: a clinical report. J Prosthodont 2001; 10: 102-104.

4) Probster L, Lin W, Hutteman H. Effect of fluoride prophylactic agents on titanium surfaces. Int J Oral Maxillofac Implants 1992; 7: 390-394

5) Ozeki K, Oda Y, Sumii T. The influence of fluoride prophylactic agents on the corrosion of titanium and titanium alloys. The Shikwa Gakuho 1996; 96: 293304.

6) Oda Y, Kawada E, Yoshinari M, Hasegawa K, Okabe $\mathrm{T}$. The influence of fluoride concentration on the corrosion of titanium and titanium alloys. Jpn J Dent Mater 1996; 15: 317-322.

7) Nakagawa M, Matsuya S, Shiraishi T, Ohta M. Effect of fluoride concentration and $\mathrm{pH}$ on corrosion behavior of titanium for dental use. J Dent Res 1999; 78: 1568-1572.

8) Pan J, Thierry D, Leygraf C. Hydrogen peroxide toward enhanced oxide growth on titanium in PBS solution: blue coloration and clinical relevance. J Biomed Mater Res 1996; 30: 393-402.

9) Pan J, Liao H, Leygraf C, Thierry D, Li J. Variation of oxide films on titanium induced by osteoblast-like cell culture and the influence of an $\mathrm{H}_{2} \mathrm{O}_{2}$ pretreatment. J Biomed Mater Res 1998; 40: 244-256.

10) Fonsecab C, Barbosa MA. Corrosion behaviour of titanium in biofluids containing $\mathrm{H}_{2} \mathrm{O}_{2}$ studied by electrochemical impedance spectroscopy. Corros Sci 2001; 43: 547-559.
11) Mabilleau G, Bourdon S, Joly-Guillou ML, Filmon R, Basle MF, Chappard D. Influence of fluoride, hydrogen peroxide and lactic acid on the corrosion resistance of commercially pure titanium. Acta Biomater 2006; 2: 121-129.

12) Abe T, Matsumoto $M$, Hattori M, Hasegawa $K$, Yoshinari M, Kawada E, Oda Y. Discoloration of titanium induced by denture cleaner. Jpn J Dent Mater 2001; 20: 366-371.

13) ISO 10271:2001 Dental metallic materials - Corrosion test methods; $10-11$

14) Oda Y, Matsuno S, Sumii T. A study of corrosion of titanium alloys used in dental work. Bull Tokyo Dent Coll 1988; 29: 59-66.

15) Johnston WM, Kao EC. Assessment of appearance match by visual observation and clinical colorimetry. J Dent Res 1989; 68: 819-822

16) Hanawa T. Characterization of surface film formed on titanium in electrolytic solutions. Jpn J Dent Mater 1989; 8: 832-844.

17) MacDonald DD, Johnson WB. Impedance spectroscopy, John Wiley and Sons, New York, 1987, pp.154156.

18) Tengvall P, Elwing H, Lundstrom I. Titanium gel made from metallic titanium and hydrogen peroxide. J Colloid Interface Sci 1989; 130: 405-413.

19) Takemoto S, Yamamoto T, Tsuru K, Hayakawa S, Osaka A, Takashima S. Platelet adhesion on titanium oxide gels: effect of surface oxidation. Biomaterials 2004; 25 : 3485-3492.

20) Wilhelmsen W, Grande AP. The influence of hydrofluoric acid and fluoride ion on the corrosion and passive behavior of titanium. Electrochim Acta 1987; 32: 1469-1472.

21) Wever DJ, Veldhuizen AG, de Vries J, Busscher HJ, Uges DR, van Horn JR. Electrochemical and surface characterization of a nickel-titanium alloy. Biomaterials 1998; 19: 761-769.

22) Rondelli G, Vicentini B. Localized corrosion behaviour in simulated human body fluids of commercial Ni-Ti orthodontic wires. Biomaterials 1999; 20: 785792.

23) Yonekura Y, Endo K, Iijima M, Ohno H, Mizoguchi I. In vitro corrosion characteristics of commercially available orthodontic wires. Dent Mater J 2004; 23: 197-202.

24) Tomashov ND, Al'tovskii RM, Chernova GP. Passivity and corrosion resistance of titanium and its alloys. J Electrochem Soc 1961; 108: 113-119.

25) Oda Y, Funasaka M, Sumii T. Corrosion of dental titanium alloys - Binary system of Ti-Al, Ti-Cu, TiNi. J J Dent Mat 1990; 9: 318-323.

26) Takada Y, Okuno O. Corrosion characteristics of alpha-Ti and $\mathrm{Ti}_{2} \mathrm{Cu}$ composing $\mathrm{Ti}-\mathrm{Cu}$ alloys. Dent Mater J 2005; 24: 610-616.

27) Brossia CS, Cragnolino GA. Effect of palladium on the corrosion behavior of titanium. Corros Sci 2004; 46: 1583-1612.

28) Takemoto S, Hattori M, Yoshinari M, Kawada E, Asami K, Oda Y. Corrosion behavior and surface characterization of $\mathrm{Ti}-20 \mathrm{Cr}$ alloy in a solution containing fluoride. Dent Mater J 2004; 23: 379-386. 